\title{
EFFECT OF THE RECYCLING PROCESS AND BINDER TYPE ON BITUMINOUS MIXTURES WITH $100 \%$ RECLAIMED ASPHALT PAVEMENT
}

Nosetti, Adrián

Associate Professor

Unidad de Investigación y Desarrollo (UIDIC), Facultad de Ingeniería, Universidad Nacional de La Plata, Argentina

Phone: 00542214236687

anosetti@ing.unlp.edu.ar

Pérez-Madrigal, Domingo

PhD Student

Road Research Laboratory, UPC-BarcelonaTech, Spain

Phone: 0034934017085

ing_domingopm@hotmail.com

Pérez-Jiménez, Félix

Professor

Road Research Laboratory, UPC-BarcelonaTech, Spain

Phone: 0034934017085

edmundo.perez@upc.edu

Martínez, Adriana H.

Associate Professor

Road Research Laboratory, UPC-BarcelonaTech, Spain

Phone: 0034934017085

adriana.martinez@upc.edu 


\begin{abstract}
There is a great interest in increasing the amount of recycled material used in asphalt mixes because of the beneficial impact on the environment. This is leading to the development of different recycling procedures, from cold in-situ to hot in-plant recycling. The objective of the study presented in this paper is to evaluate cracking resistance of recycled mixes manufactured by three types of processes, i.e., cold with emulsion, hot with high penetration bitumens and hot with emulsion (half-warm mixture), using $100 \%$ of reclaimed asphalt pavement (RAP) at different temperatures. Differences in their workability and ease of use are also analysed by gyratory compaction.
\end{abstract}

Keywords: asphalt recycling temperatures; bituminous mixture; half-warm recycled mixture; cracking resistance; Fénix test 


\section{INTRODUCTION}

The recycling of bituminous layers is a highly valued alternative for road pavement rehabilitation from the economic and environmental perspectives because it leads to savings in energy and natural resources. This technique can even bring additional advantages compared to overlaying, such as maintaining section geometry and reducing the duration of traffic disruption.

Different types of recycling processes of bituminous layers are currently used. Some consist of techniques which are consolidated and familiar because they are the oldest ones, namely hot and cold recycling of asphalt mixes. Specifications regarding these can be found in many countries (Dinis-Almeida et al., 2012). Other processes are newer techniques that produce warm and half-warm recycled mixtures about which much research is being conducted to verify the properties of the resulting mixture (Romier et al., 2006; Gaudefroy et al., 2007; Dinis-Almeida and Lopes, 2015; Lopes et al., 2015; Lu et al., 2016; Mallick et al., 2008; Punith et al., 2012; Van de Ven et al., 2007; PérezMartínez et al., 2017).

Hot recycling of an asphalt mix is the manufacture of a bituminous mixture using conventional materials (aggregates, bitumen and filler) but replacing a portion of these by material from milling of a deteriorated and aged pavement (commonly called RAP). The purpose is to achieve a mixture with similar characteristics to those of a conventional hot bituminous mix. However, the presence of RAP gives the mixture certain particular characteristics; the aged bitumen in the RAP is distinguished by its low penetration and high softening point, meaning that its cohesive properties are usually lower than those of a new bitumen. To compensate for this degree of ageing, a very soft new bitumen and even rejuvenating agents are often added, resulting in a blend of binders with acceptable properties (Yu et al., 2014).

Another property to be analysed is gradation. The addition of new aggregates corrects the gradation of the aggregates of the RAP in order to achieve the particle size distribution and void content specified for a hot asphalt mixture. Mixtures made with this RAP have no problems of plastic deformation (Pasetto and Baldo, 2014); on the contrary, the main risk of these mixtures is excessive stiffness and very low ductility. It is therefore important to evaluate the behaviour of hot recycled mixtures at low temperatures by analysing their cracking resistance (Shah et al., 2007; Daniel et al., 2010; Zaumanis et al., 2014).

As far as mixing and compaction temperature is concerned, cold recycling with emulsion is at the other end of the recycling techniques. Mixtures are manufactured from material obtained from milled bituminous layers combined with a bitumen emulsion at room temperature. From the environmental perspective, these are the most sustainable mixtures since no virgin aggregates or heating of materials are needed (Salomon and Newcomb, 2000). On the other hand, from the technical point of view, there are some disadvantages compared with hot recycled mixes, and these are a barrier to their use. During the manufacturing stage, the layer of mixtures recycled with emulsion requires very high compaction energy to densify and the water in the emulsion a long curing time to evaporate. These two requirements mean a longer construction time, and therefore a lower performance during construction (Davidson et al., 2003; 
Sebaaly et al., 2004; Kim et al., 2011). As to quality, significant differences are also found between these mixtures and hot recycled mixtures: mixtures recycled with emulsion have the advantage of being flexible, and can therefore be spread in very thin layers without cracking, but their stiffness modulus is usually very low, resulting in low resistance to traffic loads or to the action of water. For this reason, in some countries, the use of mixtures recycled with emulsion is restricted to the pavement base and binder layers of roads subjected to low intensity traffic (Jahren and Chen, 2007).

New recycling techniques have been developed in recent years to improve the performance of cold recycled mixtures with emulsion by reducing the use of bitumens or excessive heating of materials. One of these techniques involves half-warm recycled mixtures, which are obtained by heating the RAP to a temperature not exceeding $100^{\circ} \mathrm{C}$ and mixing it with a bitumen emulsion (Olard et al., 2009). In this process, the manufacturing and laying temperature is lower, thereby reducing fuel consumption and greenhouse gas emissions. Additionally, the highest possible rate of recycled material is used.

Half-warm recycled mixtures have certain advantages over cold recycled mixtures because RAP temperature favours coating and increases initial cohesion of the mixture (curing time is decreased). As a result, these mixtures have better mechanical characteristics, keep similar flexibility and can be laid in thin layers.

In summary, recycled mixture design must pay attention to mixture workability to facilitate laying and compaction, and to stiffness and ductility because of their influence on in-service behaviour of pavements.

The following study compares the above properties in recycled mixtures manufactured by the three recycling processes: hot, half-warm and cold. The mixtures were prepared with the same type of RAP without the contribution of virgin aggregates, thereby ensuring the formation of similar granular structures and keeping constant residual bitumen content.

To evaluate workability of mixtures, all specimens were manufactured using the gyratory compactor and applying the same number of gyrations and the same conditions of vertical pressure and gyration angle, and volumetric variation and shear stress were recorded during the compaction process (Martínez et al., 2007). To analyse the mechanical properties, Fénix test was applied at different temperatures to determine the number of parameters related to stiffness and ductility of mixtures (Pérez-Jiménez et al., 2010; Miró et al., 2014). This test was also used to assess cracking resistance since cracking is a typical distress associated with high RAP content mixtures, as stated by many researchers (McDaniel et al., 2000; Zaumanis et al., 2014; Pasetto and Baldo, 2017).

\section{METHODOLOGY AND EXPERIMENTAL PLAN}

The study consisted in manufacturing four recycled bituminous mixes using the same type of milled bituminous material, reclaimed asphalt pavement (RAP), without contribution of virgin aggregates, i.e., adding 100\% RAP, with bituminous binders and by different processes. Table 1 shows the experimental plan. 
Table 1. Experimental plan with number of specimens.

\begin{tabular}{lccccc}
\hline Mixture type & $\begin{array}{c}\text { Binder } \\
\text { type }\end{array}$ & $\begin{array}{c}\text { Marshall } \\
\text { specimens } \\
\text { (No.) }\end{array}$ & \multicolumn{3}{c}{$\begin{array}{c}\text { Number of Fénix } \\
\text { specimens tested at } \\
\text { (No.) }\end{array}$} \\
& & & $-5^{\circ} \mathrm{C}$ & $5^{\circ} \mathrm{C}$ & $20^{\circ} \mathrm{C}$ \\
\hline Hot recycled & $70 / 100$ & 6 & 4 & 4 & 4 \\
Hot recycled & $160 / 220$ & 6 & 4 & 4 & 4 \\
Half-warm recycled & C67B3 & 6 & 4 & 4 & 4 \\
Cold recycled & C60B5 & 6 & 4 & 4 & 4 \\
\hline
\end{tabular}

The RAP contained $4.06 \%$ of bitumen. The solid line in Figure 1 shows the RAP gradation used to manufacture the specimens. The dashed line corresponds to the gradation of aggregates after the extraction test. This figure shows how the fines are bonded by the mastic and that the RAP particles are coarser.

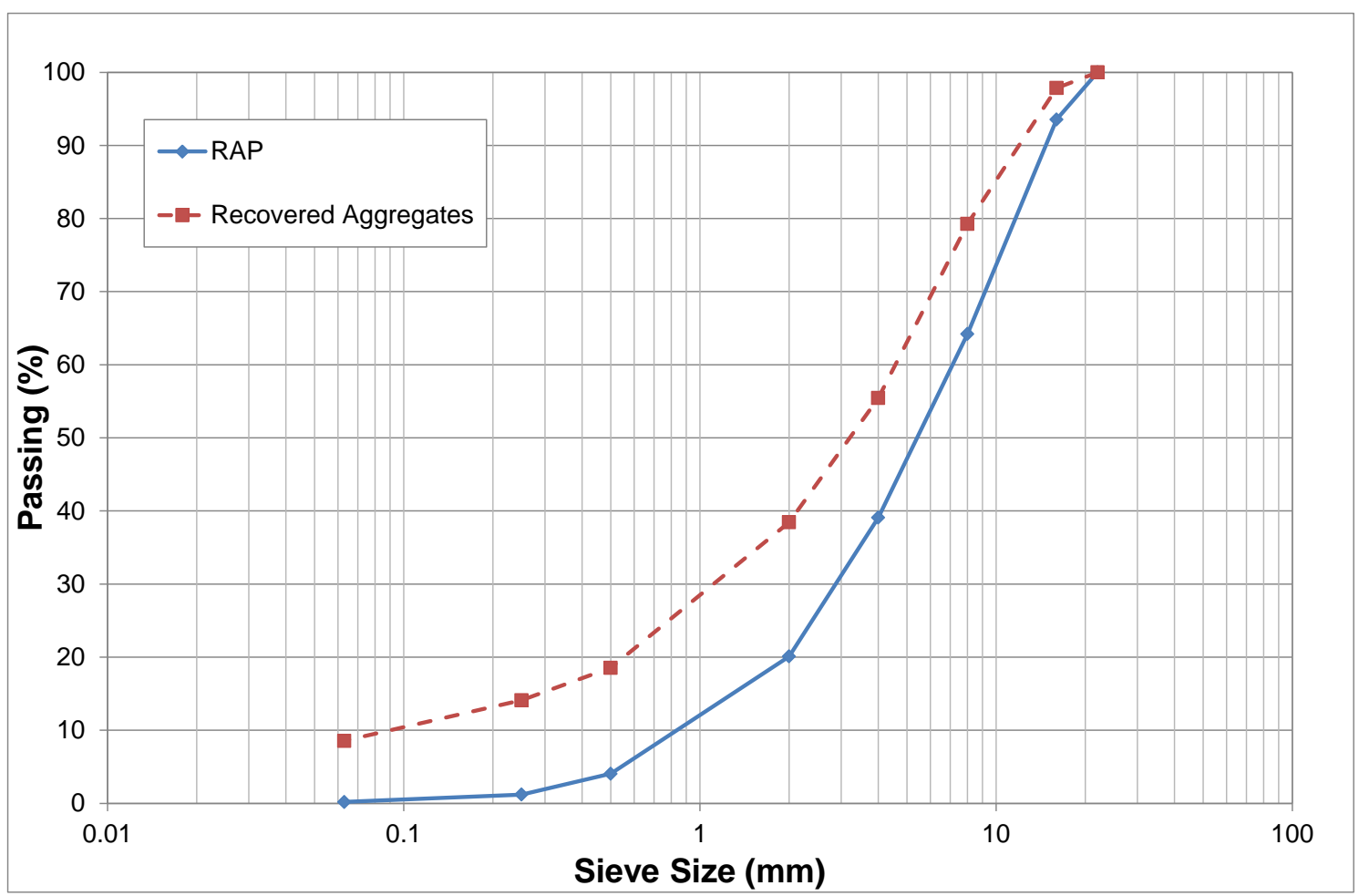

Fig. 1. Gradation of RAP and recovered aggregates.

Two of the mixtures were hot-recycled with different penetration bitumens, 70/100 and $160 / 220$, and manufactured at $145^{\circ} \mathrm{C}$. Since the function of these bitumens is to restore the lost properties of the aged bitumen of the RAP, i.e., penetration and viscosity, the degree of influence of this variable (bitumen type) on the properties to be analysed was also determined.

The other two mixtures were prepared with cationic emulsions. One was cold-recycled with C60B5 emulsion (58-62\% bitumen content and breaking index 5); the other was half-warm by heating the RAP at $100^{\circ} \mathrm{C}$ and mixing it with C67B3 emulsion (65-69\% bitumen content and breaking index 3 ). The latter emulsion has higher residual bitumen content and lower water content. 
The penetration index of the recovered binder from the RAP was 16 tenths of millimetres $(0.1 \mathrm{~mm})$ and the softening point, $84^{\circ} \mathrm{C}$. Residual bitumen content was kept constant in all cases, i.e., $5.5 \%$ by weight of mixture (5.8\% by weight of RAP), to determine the percentages of bitumen and emulsion to be incorporated in each type of mixture.

With regard to manufacturing conditions, 100 gyrations of the gyratory compactor, a piston vertical pressure of $0.6 \mathrm{MPa}$ and a gyration angle of $0.82^{\circ}$ were applied following the standard test UNE-EN 12697-31. Six replicates were manufactured for each type of mixture.

Mixtures prepared with emulsions were compacted using slotted moulds to allow drainage of water released during compaction, Figure 2.
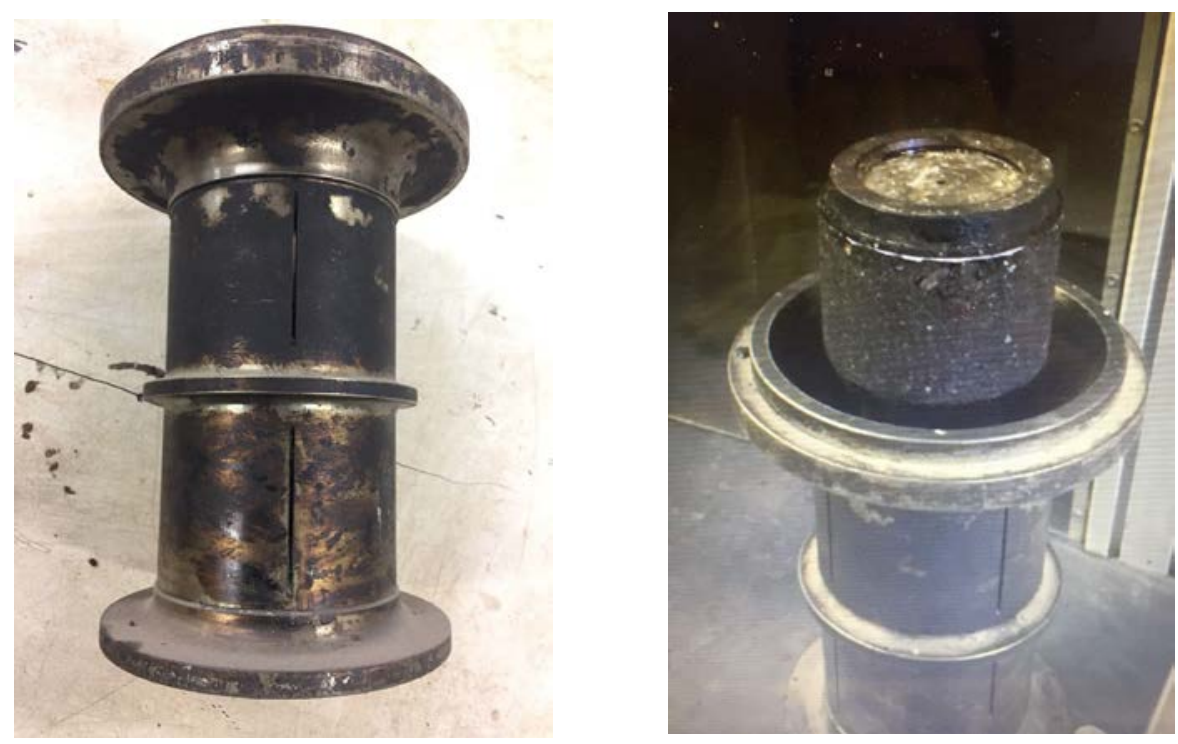

Fig. 2. Slotted moulds used for compacting mixtures.

In the case of mixtures with emulsion, coating water content was $1 \%$, obtained from Proctor compaction test (standard UNE 103501) and curing conditions were three days at $50^{\circ} \mathrm{C}$ according to the Spanish Technical Specifications for Roads Rehabilitation (PG-4, 2001).

The parameters recorded during the compaction test were the evolution of density and shear stress. At the end of the compaction process, and the curing time in the case of specimens made with emulsion, bulk density was determined by the hydrostatic method according to standard UNE-EN 12697-6.

Cracking resistance of all specimens was evaluated by Fénix test. This test determines the effort required to crack a semi-cylindrical specimen by applying a tensile stress along the diametrical plane through two metal plates glued to the specimen in the diametrical plane and subjected to the anchors of the press. The test is performed at a constant displacement speed of the piston of $1 \mathrm{~mm} / \mathrm{min}$. The specimen has a small notch between the two plates, as shown in Figure 3, which induces cracking of the specimen. The load applied and piston displacement are recorded throughout the test to determine 
tensile stiffness index (IRT), fracture energy $\left(G_{D}\right)$, toughness index (IT) and displacement at $50 \%$ of post-peak maximum load ( $\mathrm{d}_{0.5}$ PostFmax).
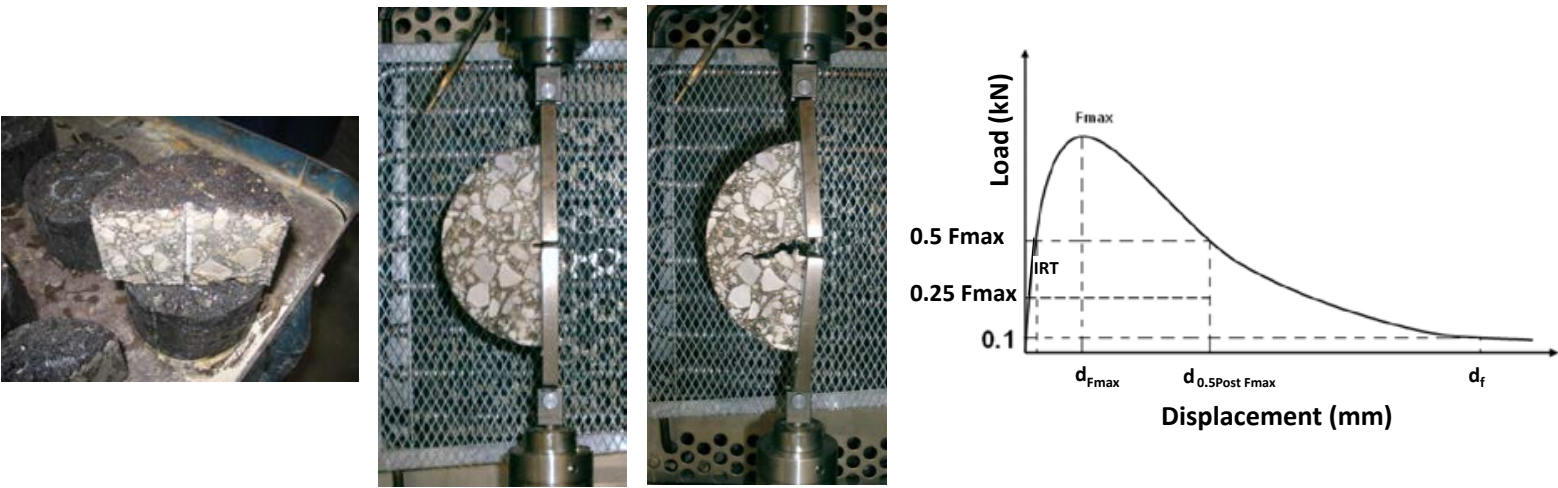

Fig. 3. Fénix test specimens and load-displacement curve.

A stiffness parameter (tensile stiffness index) is defined as the slope of the loaddisplacement curve between 25 and $50 \%$ of maximum load reached during the pre-peak portion of the test:

$$
I R T=\frac{0.5 F_{\max }-0.25 F_{\max }}{\left(d_{0.5 F \max }-d_{0.25 F_{\max }}\right)},
$$

where IRT $=$ tensile stiffness index, $\mathrm{kN} / \mathrm{mm}$; Fmax $=$ peak load, $\mathrm{kN}$; $\mathrm{d}_{0.5 F \max }=$ displacement before peak load at $1 / 2$ Fmax, mm; $\mathrm{d}_{0.25 \mathrm{Fmax}}=$ displacement before peak load at $1 / 4$ Fmax, mm.

Fracture energy during cracking, GD, is also calculated as the fracture work done (area under the load-displacement curve) divided by the fracture section:

$$
\mathrm{G}_{\mathrm{D}}=\frac{\int_{0}^{\mathrm{d}_{\mathrm{f}}} \mathrm{F}(\mathrm{x}) \mathrm{dx}}{\mathrm{S}},
$$

where $\mathrm{G}_{\mathrm{D}}=$ fracture energy, $\mathrm{J} / \mathrm{m}^{2} ; \mathrm{F}=$ load, $\mathrm{kN} ; \mathrm{df}=$ displacement at $\mathrm{F}=0.1 \mathrm{kN}$ postpeak load, $\mathrm{mm}$ (considered as a residual value); $\mathrm{x}=$ vertical actuator displacement $(\mathrm{mm}) ; \mathrm{S}=$ fracture section $\left(\mathrm{m}^{2}\right)$.

Two ductility related parameters can be obtained, namely toughness index (IT) and displacement at $50 \%$ of post-peak maximum load, $\mathrm{d}_{0.50}$ Post Fmax. IT quantifies the ductility of the material by multiplying the width of the softening curve by the dissipated energy once the maximum load is reached. The $\mathrm{d}_{0.50}$ Post Fmax provides similar information since it is also directly related to the width of the softening curve:

$$
\mathrm{IT}=\frac{\int_{\mathrm{d}_{\mathrm{Fmax}}}^{\mathrm{d}_{\mathrm{f}}} \mathrm{F}(\mathrm{x}) \mathrm{dx}}{\mathrm{S}} \cdot\left(\mathrm{d}_{0.5 \text { PostFmax }}-\mathrm{d}_{\mathrm{Fmax}}\right) .
$$

Fenix test was compared with Semi-Circular Bend (SCB) test in the assessment of fracture behaviour of different types of mixtures. Both tests gave similar results about the effect of loading rate and temperature (Pérez-Jiménez et al., 2013). 
Test temperatures were $-5^{\circ} \mathrm{C}, 5^{\circ} \mathrm{C}$ and $20^{\circ} \mathrm{C}$ to evaluate the response of the mixtures in a wide range of temperatures. The six Marshall specimens obtained with the gyratory compactor allowed twelve semi-cylindrical specimens to be obtained. Thus, four replicates were tested with each mixture type for each test temperature.

\section{RESULTS AND DISCUSSION}

\subsection{Results of gyratory compaction}

The evolution of density with the number of gyrations can be seen in Figure 4, which shows a clear difference between the density of the cold recycled mixture and the other three mixtures. The lower density of the cold mixture is kept until the end of compaction, resulting in a mixture with higher void content. As Figure 5 shows, the effort made to compact the cold mixture is higher than that used for the other mixtures.

The half-warm recycled mixture and the hot recycled mixtures behaved similarly, demonstrating that heating the RAP improved workability of mixtures with emulsion and reduced shear stress required to densify the mixture.

The results for the two hot recycled mixtures indicate that both were compacted in a similar manner irrespective of type of bitumen.

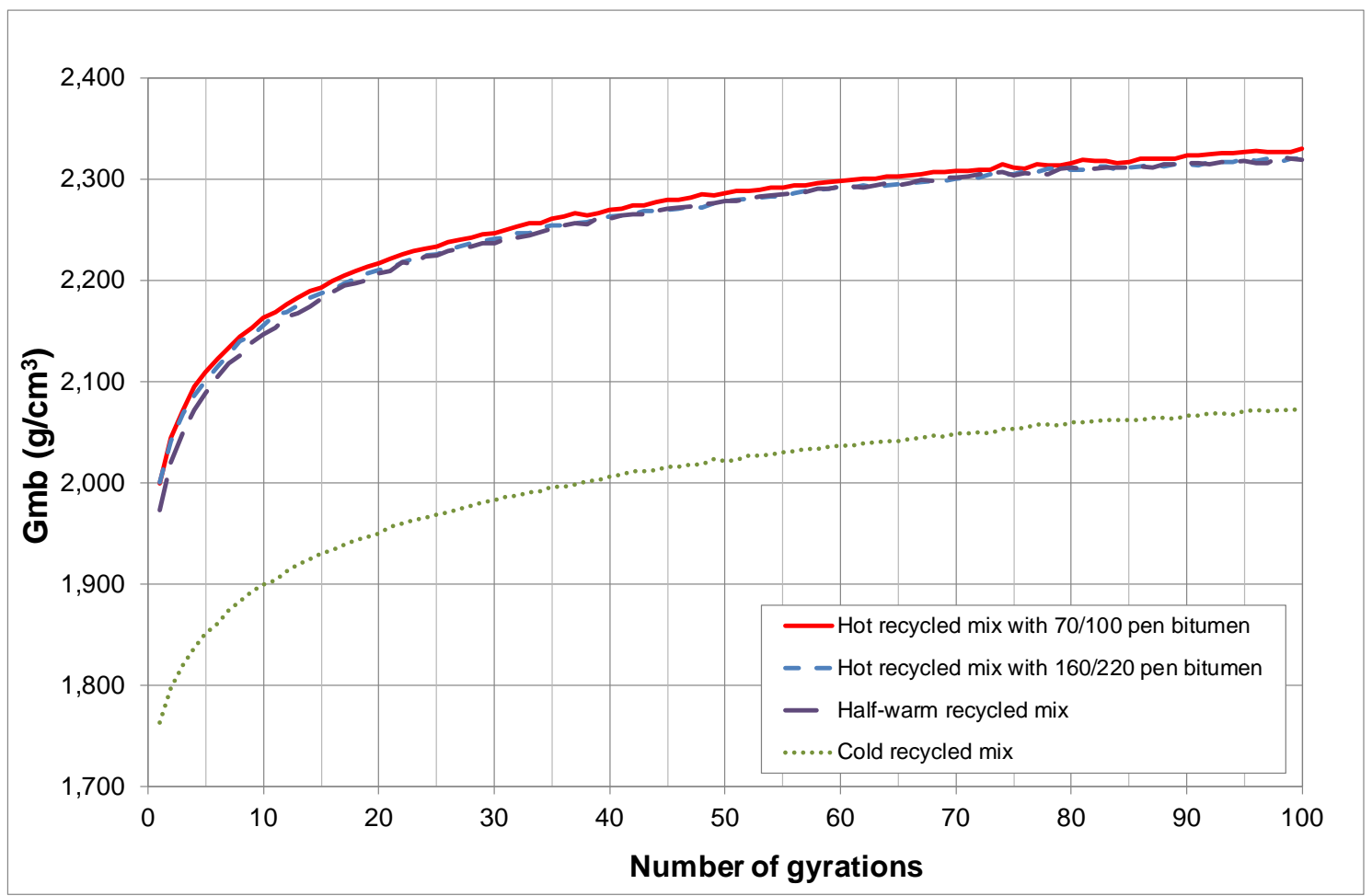

Fig. 4. Evolution of density during gyratory compaction. 


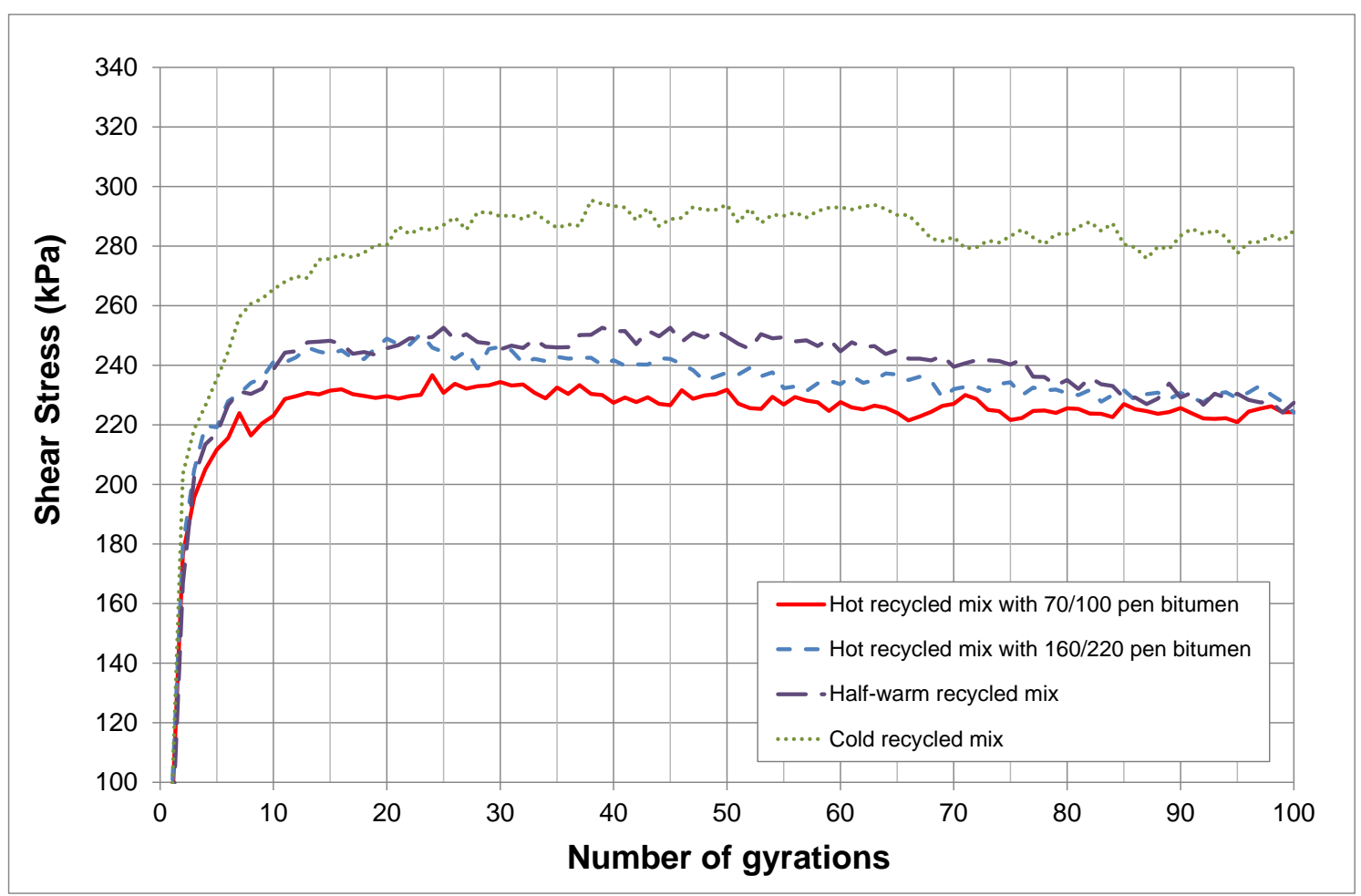

Fig. 5. Evolution of shear stress during gyratory compaction.

The results of bulk densities, theoretical maximum specific density (Gmm), air void content and shear strength at the end of compaction are collected in Table 2.

Table 2. Parameters obtained from the compacted specimens.

\begin{tabular}{lccccc}
\hline Mix type & $\begin{array}{c}\text { Bulk } \\
\text { Density } \\
\left(\mathrm{g} / \mathrm{cm}^{3}\right)\end{array}$ & $\begin{array}{c}\text { Maximum } \\
\text { Density } \\
\mathrm{Gmm} \\
\left(\mathrm{g} / \mathrm{cm}^{3}\right)\end{array}$ & $\begin{array}{c}\% \mathrm{Gmm} \\
(\%)\end{array}$ & $\begin{array}{c}\text { Air } \\
\text { Voids } \\
(\%)\end{array}$ & $\begin{array}{c}\text { Shear } \\
\text { Strength } \\
(\mathrm{kPa})\end{array}$ \\
\hline Hot recycled with 70/100 pen bitumen & 2.328 & 2.484 & 93.7 & 6.3 & 224.3 \\
Hot recycled with 160/220 pen bitumen & 2.329 & 2.478 & 94.0 & 6.0 & 224.1 \\
Half-warm recycled mix & 2.318 & 2.460 & 94.2 & 5.8 & 227.4 \\
Cold recycled mix & 2.083 & 2.481 & 83.9 & 16.1 & 285.3 \\
\hline
\end{tabular}

Given the great difference in the compaction degree between the cold mixture and the hot and half-warm mixtures, it is evident that the compaction indices designed for hot mixes (Dessouky et al., 2012; Anderson et al., 2002), such as N92 (number of gyrations the compactor takes to reach 92\% Gmm), workability energy index WEI (energy necessary to compact a sample from zero gyrations to N92\% Gmm) or construction densification index CDI (area under the densification curve from 8 gyrations to N92\% Gmm gyrations) cannot be applied.

\subsection{Results of Fénix test}

\subsubsection{Relationship of load-displacement with temperature effect}

The influence of test temperature on the behaviour of tested mixtures is shown by the load-displacement plots obtained from Fénix test, Figures $6 \mathrm{a}, 6 \mathrm{~b}$ and $6 \mathrm{c}$. At $20^{\circ} \mathrm{C}$, hot recycled mixtures reach the highest maximum load while mixtures with emulsions have 
different behaviours. The half-warm recycled mixture reaches a higher maximum load than the cold recycled mixture but a lower load than the hot recycled mixtures.

At $5^{\circ} \mathrm{C}$, the load-displacement curve stresses the value of maximum load and ductility degree is lower than those recorded at $20^{\circ} \mathrm{C}$ for all mixtures. Regarding hot recycled mixes, the one manufactured with 70/100 pen bitumen has a higher maximum load than the one manufactured with the softer 160/220 pen bitumen, although the slopes of the curves for hot and half-warm recycled mixtures are very similar, indicating that stiffness is of the same order in all three cases.

At $-5^{\circ} \mathrm{C}$, both hot and half-warm recycled mixtures behave similarly while the cold recycled mixture has a different response, with lower maximum load and stiffness.

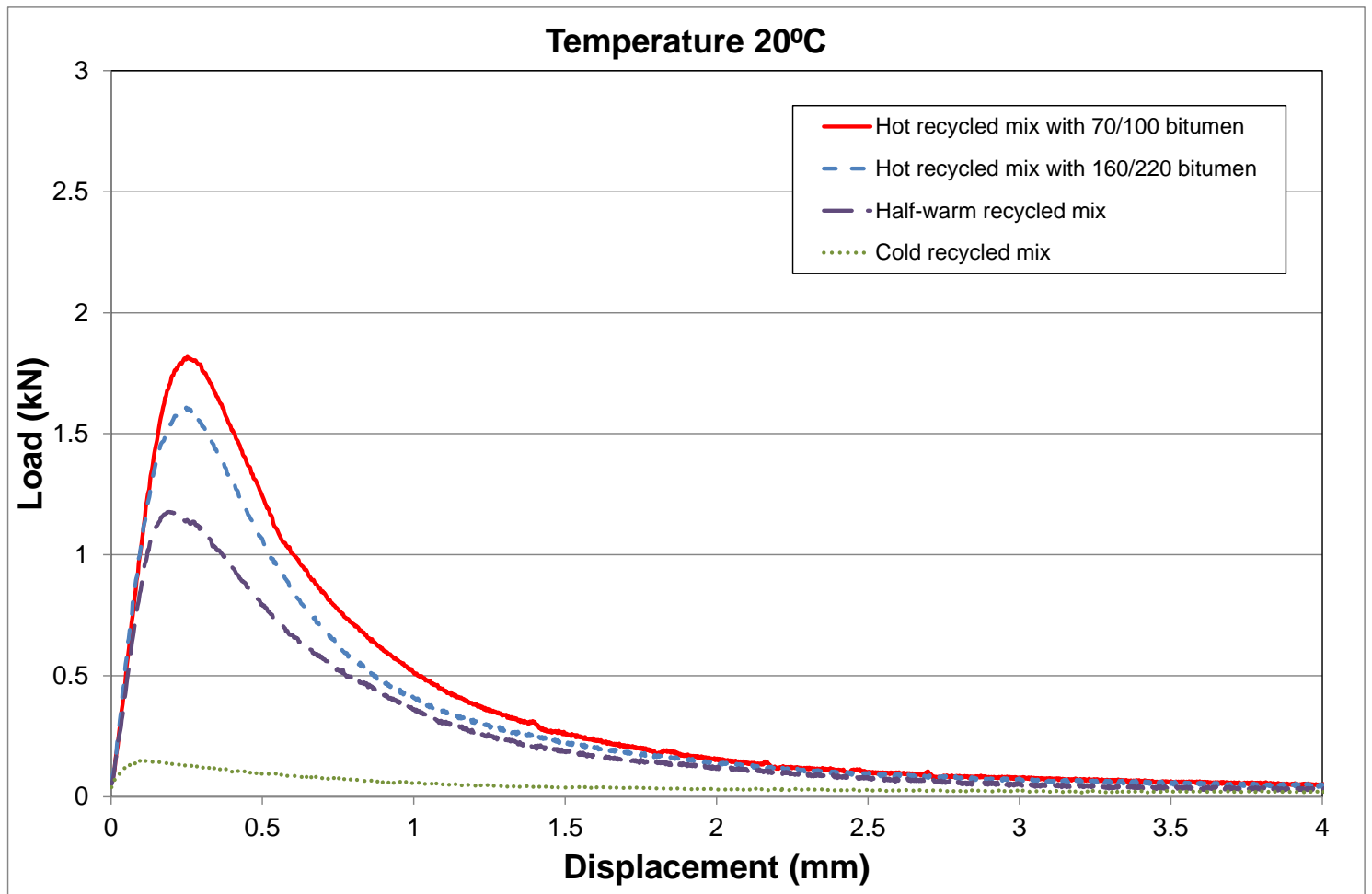

Fig. 6a. Load-displacement curve at $20^{\circ} \mathrm{C}$, Fénix test. 


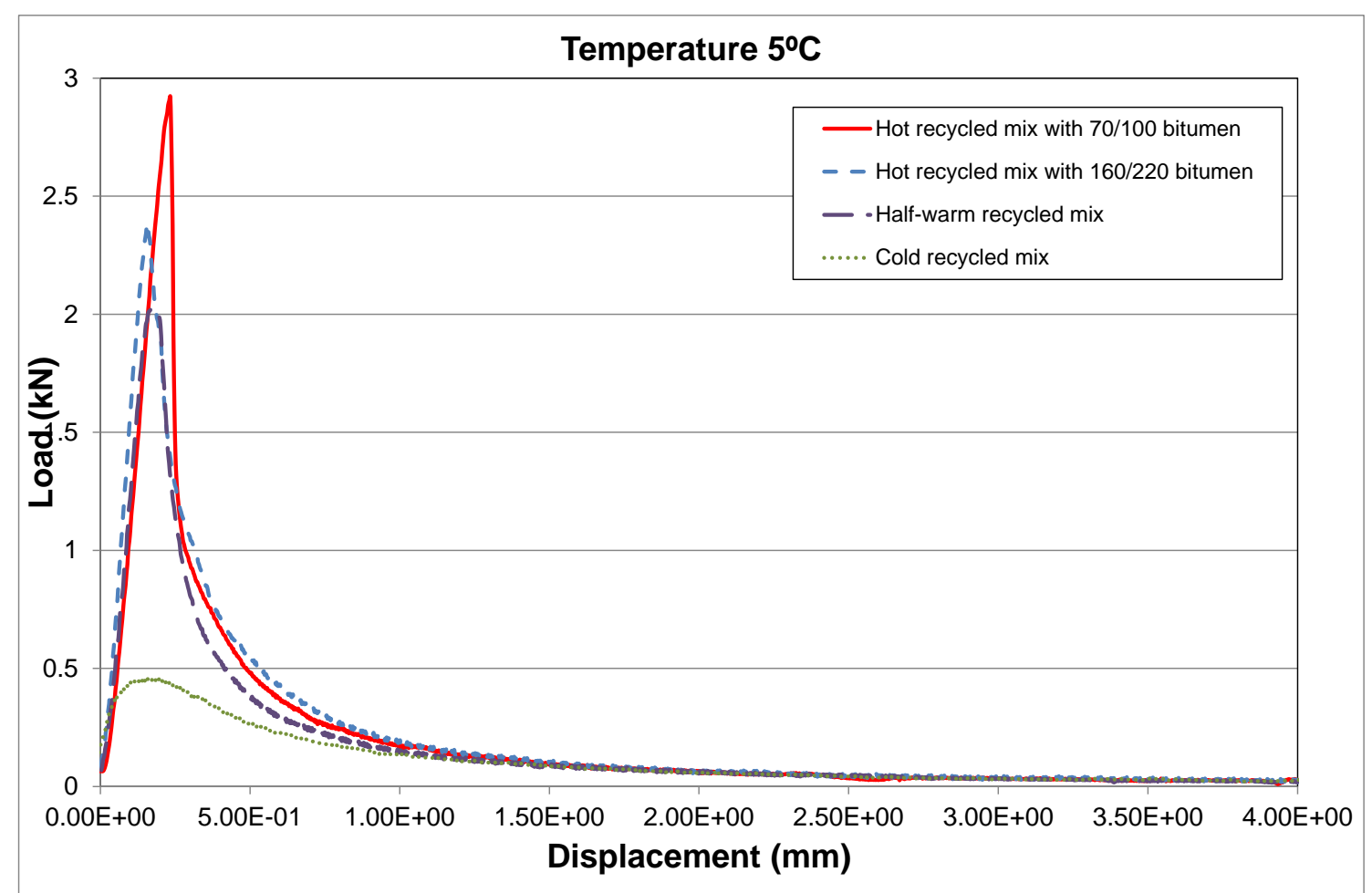

Fig. 6b. Load-displacement curve at $5^{\circ} \mathrm{C}$, Fénix test.

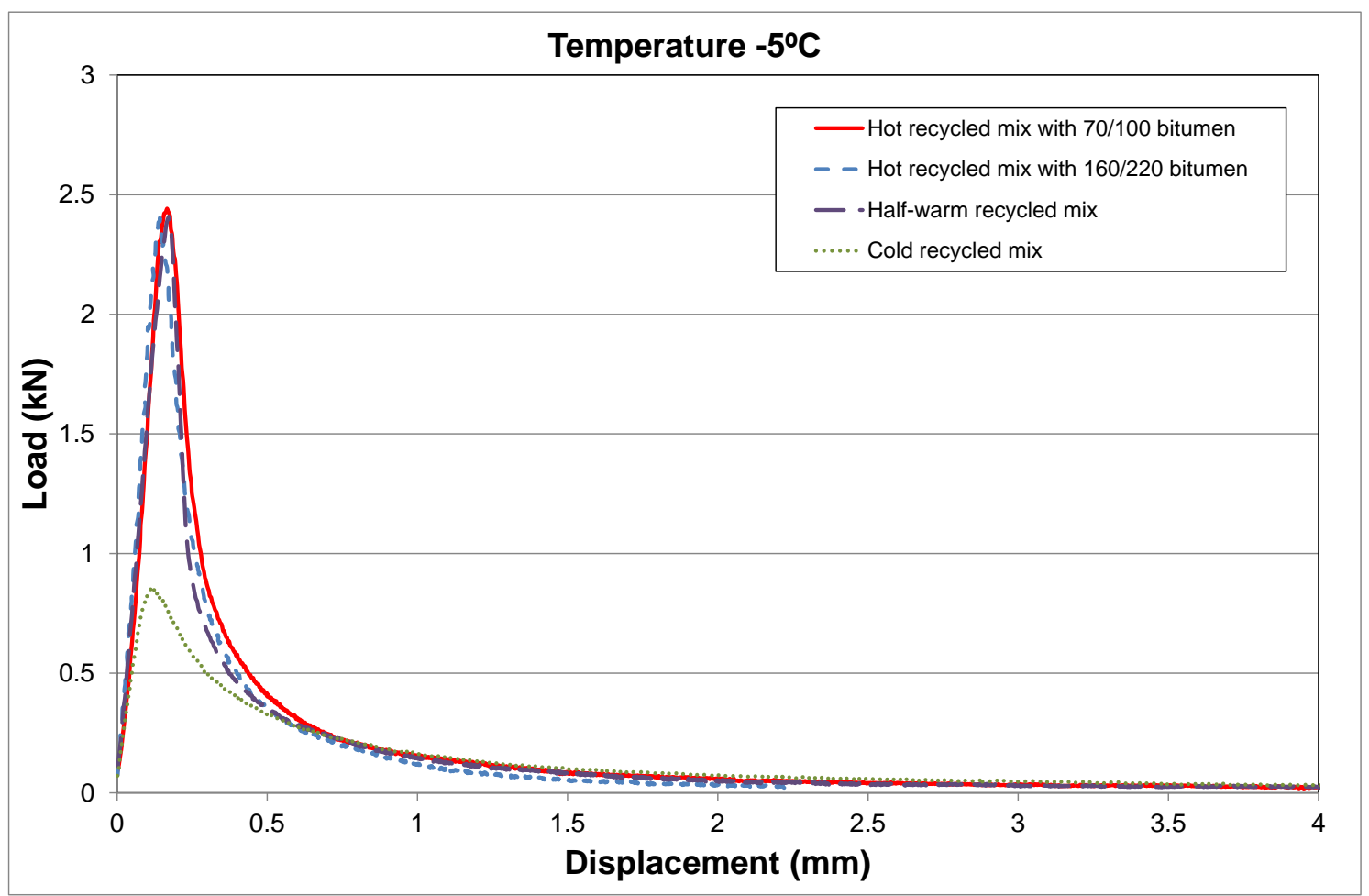

Fig. 6c. Load-displacement curve at $-5^{\circ} \mathrm{C}$, Fénix test.

\subsubsection{Analysis of the parameters obtained from Fénix test}

The variation of the parameters obtained from Fénix test as a function of the temperature makes it possible to analyse and compare the response of mixtures with different types of binders and the corresponding manufacturing temperatures. 
The results are analysed in comparison with the criteria proposed by the Road Research Laboratory of the Technical University of Catalonia (UPC) for the design of conventional dense bituminous mixtures, called asphalt concrete (AC) mixtures, in order to identify tough and cracking resistant mixtures (Pérez-Jiménez et al., 2014). These criteria are based on looking for maximum toughness provided that the mixture retains a minimum void content, stiffness modulus and fracture energy. The proposed parameters and values are shown in Table 3.

Table 3. Design criteria proposed for asphalt concrete (AC) mixtures.

\begin{tabular}{llc}
\hline Parameter & & Value \\
\hline Void Content $(\%)$ & $>4$ \\
\multicolumn{2}{l}{ Tensile Stiffness Index $(\mathrm{IRT})(\mathrm{kN} / \mathrm{mm})$} & $>2.5$ \\
Fracture Energy $\left(\mathrm{G}_{\mathrm{D}}\right)\left(\mathrm{J} / \mathrm{m}^{2}\right)$ & & $>200$ \\
Toughness Index $(\mathrm{IT})\left(\mathrm{J} / \mathrm{m}^{2}\right) . \mathrm{mm}$ & Acceptable & $>75$ \\
& Recommended & $>150$ \\
& Ductile Mixtures & $>200$ \\
Displ. at 50\% of post-peak max. load & Acceptable & $>0.4$ \\
$\mathrm{~d}_{0.5}$ PostFmax $(\mathrm{mm})$ & Recommended & $>0.8$ \\
& Ductile Mixtures & $>1.0$ \\
\hline
\end{tabular}

The application of these criteria leads to variations in mixture ductility and stiffness with temperature. The criteria are addressed to the design of ductile and cracking resistant mixtures at a temperature of $20^{\circ} \mathrm{C}$.

The variations in tensile stiffness index (IRT), displacement at $50 \%$ post-peak maximum load $\left(\mathrm{d}_{0.5}\right.$ PostFmax $)$ and fracture energy $\left(\mathrm{G}_{\mathrm{D}}\right)$ as a function of the temperature can be seen in Figures 7 and 8. Toughness index results are not shown because the trends obtained are similar to those of $\mathrm{d}_{0.5}$ PostFmax.

Figure 7 shows that it is possible to manufacture half-warm recycled mixtures with similar stiffness and ductility to those achieved by the hot recycled mixtures at the three test temperatures: $20^{\circ} \mathrm{C}, 5^{\circ} \mathrm{C}$ and $-5^{\circ} \mathrm{C}$. The results for the cold recycled mixture show a clearly different behaviour, with an approximate 50\% decrease in stiffness throughout the whole temperature range and an increase in displacement at $50 \%$ of post-peak maximum load, which is more pronounced at $5^{\circ} \mathrm{C}$.

Comparison of these results with the limits proposed for conventional mixtures shows that all mixtures have enough stiffness because of the RAP addition, and so they amply exceed the minimum IRT required. As for displacement at $50 \%$ of post-peak maximum load, all mixtures also meet the minimum value of $0.4 \mathrm{~mm}$ at $20^{\circ} \mathrm{C}$ while at lower temperatures hot and half-warm recycled mixtures exhibit a significant reduction of ductility. 


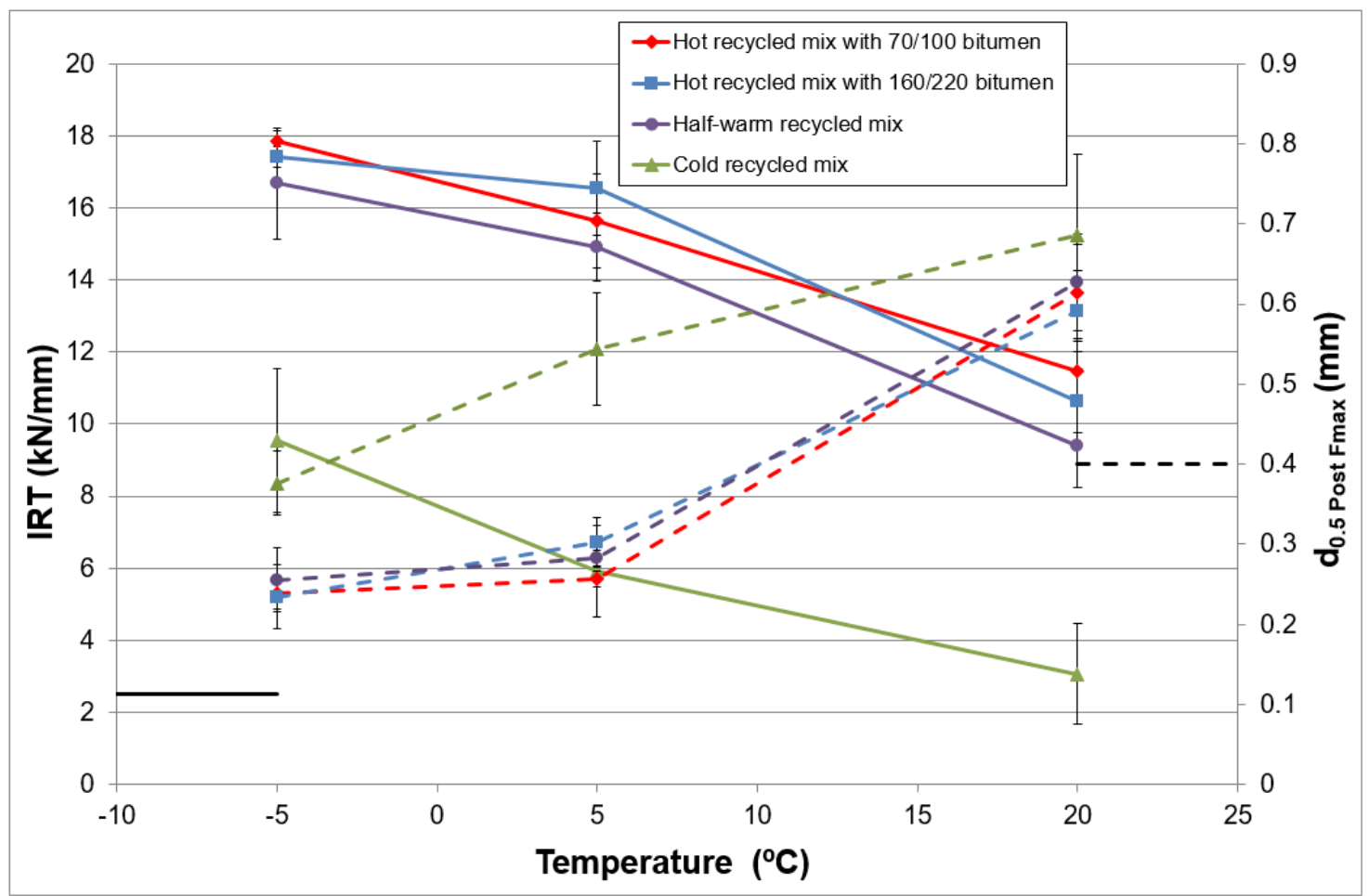

Fig. 7. Variation of Tensile Stiffness Index (IRT) and Displacement at 50\% of post-peak maximum load ( $\mathrm{d}_{0.5}$ Post Fmax $)$ with temperature, Fénix test.

Figure 8 illustrates the variation of fracture energy and displacement at $50 \%$ of the postpeak maximum load with temperature. Both hot and half-warm recycled mixtures meet the minimum proposed energy requirement of $200 \mathrm{~J} / \mathrm{m}^{2}$ but the cold recycled mixture has much lower energy values throughout the temperature range and does not meet those specified for hot recycled mixtures. Moreover, this mixture exhibits an opposite behaviour to that of the other mixtures, i.e., energy decreases as temperature increases, leading to a much more flexible response at low temperatures. 


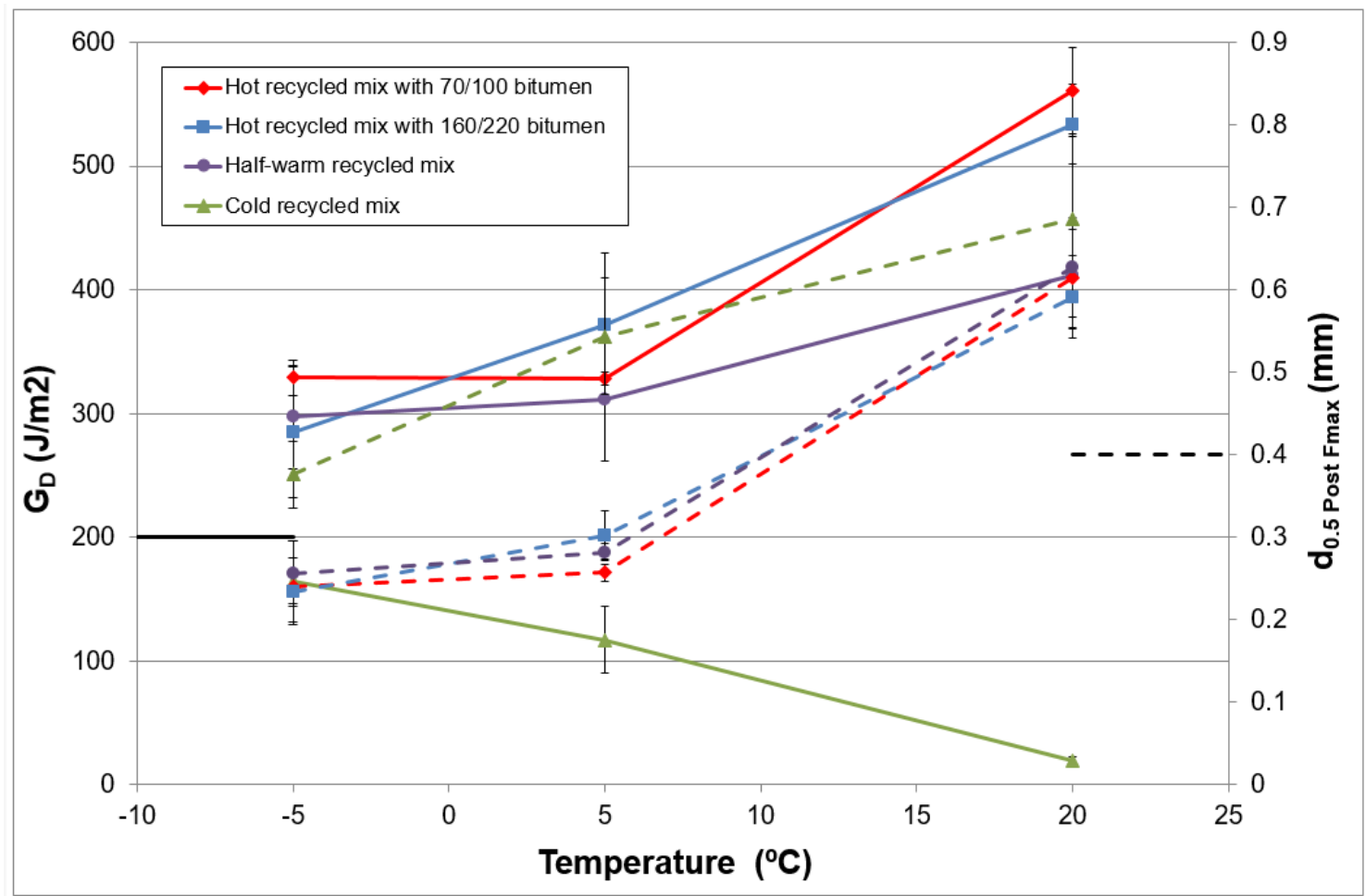

Fig. 8. Variation of Fracture Energy $\left(\mathrm{G}_{\mathrm{D}}\right)$ and Displacement at $50 \%$ of post-peak maximum load ( $\mathrm{d}_{0.5}$ Post Fmax $)$ with temperature, Fénix test.

Average values of the four replicates for each condition, together with error bars, are plotted in Figures 7 and 8. The coefficient of variation for the hot and half-warm recycled mixtures is lower than or equal to $10 \%$, and higher dispersion is observed in cold recycled mixtures, $15 \%$ on average. Moreover, the results for the cold recycled mixtures show significant differences with the three other mixtures.

\section{CONCLUSIONS}

The aim of this study was to compare the mechanical response of four recycled mixtures made by three different processes: hot recycling, cold recycling and hot with emulsion (half-warm mixture).

To this end, Fénix test was carried out at different temperatures. The workability of mixtures by gyratory compaction was also evaluated. RAP content and nature, as well as the total amount of bitumen, were kept constant in order to compare the results of the four mixtures.

The analysis of shear stress during mixture compaction by the gyratory compactor confirmed the lowest workability of cold recycled mixtures and how this problem can be solved by heating the aggregates. It also showed that half-warm recycled mixes can reach very similar densities to those of hot recycled mixtures.

Moreover, the validity of the criteria established from the Fénix test for the design of conventional bituminous mixtures was confirmed. These criteria ensure minimum stiffness, fracture energy and ductility to guarantee cracking resistance. 
It was also observed that hot recycled mixtures can meet the specified criteria, but great caution must be taken with the ductility of mixtures at low temperatures as this property becomes critical from $12^{\circ} \mathrm{C}$.

In the case of half-warm recycled mixtures, it was confirmed that they can behave almost like hot recycled mixes in terms of stiffness and ductility.

Finally, ductility of cold recycled mixtures was found to be much higher than that of hot and half-warm recycled mixtures, as expected. On the other hand, stiffness was significantly lower, specifically about half the value for hot and half-warm recycled mixtures.

These results are consistent with the field of application of cold and hot recycling. Cold in-situ recycling can be used in roads subjected to low intensity traffic, where bituminous layers are thin and must be very flexible and ductile. In the case of hot inplant recycling, a mixture with similar stiffness and mechanical behaviour to those of a conventional mixture is sought.

\section{REFERENCES}

Anderson, R. M., Turner, P. A., Peterson, R. L., and Mallick, R. B., 2002. Relationship of Superpave gyratory compaction properties to HMA rutting behavior. NCHRP Rep. No. 478, Transportation Research Board, National Research Council, Washington, D.C.

Daniel, J., Pochily, J., Boisvert, D., 2010. Can more reclaimed asphalt pavement be added? Study of extracted binder properties from plant-produced mixtures with up to 25\% reclaimed asphalt pavement. Transportation Research Record: Journal of the Transportation Research Board, 2180, 19-29.

Davidson, J. K., Croteau, J. M., 2003. Best practices in cold in-place recycling. Annual Meeting Asphalt Emulsion Manufacturers Association Nashville March 2003.

Dessouky, S., Pothuganti, A., Walubita, L. F., Rand, D., 2012. Laboratory evaluation of the workability and compactability of asphaltic materials prior to road construction. Journal of Materials in Civil Engineering, 25(6), 810-818.

Dinis-Almeida, M., Castro-Gomes, J., de Lurdes Antunes, M., 2012. Mix design considerations for warm mix recycled asphalt with bitumen emulsion. Construction and Building Materials, 28(1), 687-693.

Dinis-Almeida, M., Lopes-Afonso, M., 2015. Warm Mix Recycled Asphalt - a sustainable solution. Journal of Cleaner Production, 107, 310-316.

Gaudefroy, V., Olard, F., Cazacliu, B., de La Roche, C., Beduneau, E., Antoine, J., 2007. Laboratory investigations of mechanical performance of foamed bitumen mixes that use half-warm aggregates. Transportation Research Record: Journal of the Transportation Research Board. 
Jahren, C. T., Chen, D., 2007. Evaluation of long-term field performance of cold inplace recycled roads: Field and laboratory testing (No. IHRB Project TR-502).

Kim, Y., S. Im, Lee, H., 2011. Impacts of Curing Time and Moisture Content on Engineering Properties of Cold In-Place Recycling Mixtures Using Foamed or Emulsified Asphalt. Journal of Materials in Civil Engineering, 23, No. 5, 1-13.

Lopes, M., Gabet, T., Bernuci, L., Mouillet, V., 2015. Durability of hot and warm asphalt mixtures containing high rates of reclaimed asphalt al laboratory scale. Materials and Structures, 48, 3937-3948.

Lu, X. D., Saleh, M., 2016. Evaluation of warm mix asphalt performance incorporating high RAP content. Canadian Journal of Civil Engineering, 43(4), 343-350.

Mallick, R., Kandhal, P., Bradbury, R., 2008. Using warm-mix asphalt technology to incorporate high percentage of reclaimed asphalt pavement material in asphalt mixtures. Transportation Research Record: Journal of the Transportation Research Board, 2051, 71-79.

Martínez, A. H., Miró, J. R., Pérez-Jiménez, F. E., 2007. Spanish experience with the application of gyratory compactor and indirect tensile test in design and control of cold recycled asphalt pavement. Transportation Research Record: Journal of the Transportation Research Board, 2001, 163-168.

McDaniel, R. S., Soleymani, H., Anderson, R. M., Turner, P., and Peterson, R. (2000). Recommended Use of Reclaimed Asphalt Pavement. The Superpave Mix Design Method. NCHRP Web document, 30.

Miró, R., Martínez, A. H., Pérez-Jiménez, F., Botella, R., 2014. Analysis of cracking resistance of bituminous mixtures using Fenix test. Construction and Building Materials, 59, 32-38.

Olard, F., Beduneau, E., Seignez, N., Dupriet, S., Bonneau, D., 2009. Laboratory performance-based assessment of half-warm mix asphalts with high recycling rate by means of the factorial experiment design approach. Proceedings of the 7th International RILEM Symposium on Advanced Testing and Characterization of Bituminous Materials, Rhodes, 651-660.

Pasetto, M., Baldo, N., 2014. Resistance to permanent deformation of base courses asphalt concretes made with RAP aggregate and steel slag. Asphalt Pavements Proceedings of the International Conference on Asphalt Pavements, ISAP 2014, Volume 2, pp. 1199-1208, ISBN: 978-1-138-02712-1.

Pasetto, M., Baldo, N., 2017. Unified approach to fatigue study of high performance recycled asphalt concretes. Materials and Structures, Volume 50, Issue 2, Article number 113, p. 1-15, DOI: 10.1617/s11527-016-0981-7.

Pérez-Jiménez, F. E., Valdés Vidal, G., Muñoz, M., Miró Recasens, J. R., Martínez Reguero, A. H., Botella Nieto, R., Amorós Parras, J., 2014. Criterios y especificaciones para el uso del ensayo Fénix en el diseño de mezclas bituminosas tipo AC. "Design 
criteria proposed for asphalt concrete (AC) mixtures”. Asociación Española de Fabricantes de Mezclas Asfálticas, IX Jornada Nacional ASEFMA 2014: el Estado del Pavimento en la Vida de los Ciudadanos, 1-16.

Pérez-Jiménez, F., Botella, R., Moon, K. H., Marasteanu, M., 2013. Effect of load application rate and temperature on the fracture energy of asphalt mixtures. Fénix and semi-circular bending tests. Construction and Building Materials, 48, 1067-1071.

Pérez-Jiménez, F., Valdés, G., Miró, R., Martínez, A., Botella, R., 2010. Fénix Test: Development of a new test procedure for evaluating cracking resistance in bituminous mixtures. Transportation research record: Journal of the Transportation Research Board, 2181, 36-43.

Pérez-Martínez, M., Marsac, P., Gabet, T., Pouget, S., Hammoum, F., 2017. Ageing evolution of foamed warm mix asphalt combined with reclaimed asphalt pavement. Materiales de Construcción, Vol. 67, Issue 327, e125 ISSN-L: 0465-2746, DOI: http://dx.doi.org/10.3989/mc.2017.04716.

PG-4, 2001. Pliego de Prescripciones Técnicas Generales para Obras de Conservación de Carreteras. Ministerio de Fomento, Madrid, Spain.

Punith, V. S., Xiao, F., Wingard, D., 2012. Performance characterization of half warm mix asphalt using foaming technology. Journal of Materials in Civil Engineering, 25(3), 382-392.

Romier, A., Audeon, M., David, J., Martineau, Y., Olard, F., 2006. Low-energy asphalt with performance of hot-mix asphalt. Transportation Research Record: Journal of the Transportation Research Board, 1962, 101-112.

Salomon, A., Newcomb, D. E., 2000. Cold in-place recycling literature review and preliminary mixture design procedure (No. MN/RC-2000-21).

Sebaaly, P., Bazi, G., Hitti, E., Weitzel, D., Bemanian, S., 2004. Performance of cold in-place recycling in Nevada. Transportation Research Record: Journal of the Transportation Research Board, 1896, 162-169.

Shah, A., McDaniel, R. S., Huber, G., Gallivan, V., 2007. Investigation of properties of plant-produced RAP mixtures. Transportation Research Record: Journal of the Transportation Research Board, 1998, 103-111.

Van de Ven, M. F. C., Jenkins, K. J., Voskuilen, J. L. M., Van Den Beemt, R., 2007. Development of (half-) warm foamed bitumen mixes: state of the art. International Journal of Pavement Engineering, 8(2), 163-175.

Yu, X., Zaumanis, M., Dos Santos, S., Poulikakos, L. D., 2014. Rheological, microscopic, and chemical characterization of the rejuvenating effect on asphalt binders. Fuel, 135, 162-171.

Zaumanis, M., Mallick, R. B., Frank, R., 2014. 100\% recycled hot mix asphalt: A review and analysis. Resources, Conservation and Recycling, 92, 230-245. 
Zaumanis, M., Mallick, R. B., Poulikakos, L., Frank, R., 2014. Influence of six rejuvenators on the performance properties of Reclaimed Asphalt Pavement (RAP) binder and 100\% recycled asphalt mixtures. Construction and Building Materials, 71, 538-550. 